\title{
INNOVATION AND ADOPTION OF MOBILE TECHNOLOGY IN PUBLIC ORGANIZATIONS: THE IBGE CASE
}

\author{
INOVAÇÃO E ADOÇÃO DE TECNOLOGIA MÓVEL EM ORGANIZAÇÕES PÚBLICAS: O CASO IBGE \\ INNOVACIÓN Y ADOPCIÓN DE TECNOLOGÍA MÓVIL EN ORGANIZACIONES PÚBLICAS: EL CASO IBGE
}

\begin{abstract}
The use of Mobile and Wireless Information Technologies (MWIT) for provisioning public services by a government is a relatively recent phenomenon. This paper evaluates the results of MWIT adoption by IBGE (The Brazilian Institute of Geography and Statistics) through a case study. In 2007, IBGE applied 82,000 mobile devices (PDAs) for data gathering in a census operation in Brazil. A set of challenges for a large scale application of MWIT required intensive work involving innovative working practices and service goals. The case reveals a set of outputs of this process, such as time and cost reductions in service provision, improved information quality, staff training and increased organizational effectiveness and agility.
\end{abstract}

KEYWORDS Mobile and wireless information technologies, IT adoption, census, organizational processes, information systems evaluation

\begin{abstract}
Amarolinda lara da Costa Zanela Saccol aczanela@unisinos.br
Professor and Researcher at the Post Graduate Program in Business Administration, Universidade do Vale do Rio dos Sinos - São Leopoldo - RS, Brazil
\end{abstract}

Adriana Manica manica100@hotmail.com

Master at the Post Graduate Program in Business Administration, Universidade do Vale do Rio dos Sinos - São Leopoldo - RS, Brazil

Silvia Elaluf-Calderwood s.m.elaluf-calderwood@lse.ac.uk

Research Associate at The London School of Economics and Political Science - London, United Kingdom

Submitted 31.03.2010. Approved 14.10.2010

Evaluated in a double blind review

Scientific Editor: Eduardo Diniz, Marlei Pozzebon and Nicolau Reinhard

RESUMO O uso das Tecnologias de Informação Móveis e sem Fio (TIMS) para o fornecimento de serviços públicos pelos governos é um fenômeno institucional relativamente recente. Este artigo avalia os resultados de adoção de tecnologias móveis pelo IBGE (Instituto Brasileiro de Geografia e Estatística), por meio de um estudo de caso. Em 2007 o IBGE aplicou 82,000 dispositivos móveis (PDAs) para coletar dados em uma ampla operação censitária no Brasil. Os desafios da implantação das TIMS em larga escala demandaram um intenso trabalho envolvendo práticas inovadoras e metas de serviço. O caso estudado revela um conjunto de resultados deste processo, tais como a redução de tempo e de custos no fornecimento de serviços, melhorias na qualidade da informação, qualificação da equipe e aumento da eficiência e agilidade organizacional.

PALAVRAS-CHAVE Tecnologia da informação móvel e sem fio, adoção de TI, censo, processos organizacionais, avaliação de sistemas de informação

RESUMEN El uso de las Tecnologías de Información Móviles e Inalámbricas (TIMI) para el suministro gubernamental de servicios públicos es un fenómeno institucional relativamente reciente. Este artículo evalúa los resultados de la adopción de tecnologías móviles realizada por el IBGE (Instituto Brasileño de Geografía y Estadística), por medio de un estudio de caso. En 2007 el IBGE aplicó 82.000 dispositivos móviles (PDA) para recolectar datos en una amplia operación censitaria en Brasil. Los desafíos de la implantación de las TIMI en gran escala demandaron un intenso trabajo, que incluyó prácticas innovadoras y metas de servicio. El caso estudiado revela un conjunto de resultados de este proceso, tales como la reducción de tiempo y de costos en el suministro de servicios, mejorías en la calidad de la información, cualificación del equipo y aumento de la eficiencia y agilidad organizacional.

PALABRAS CLAVE Tecnología de la información móvil e inalámbrica, adopción de TI, servicios públicos, procesos organizacionales, evaluación de sistemas de información 


\section{INTRODUCTION}

In the last two decades, the world witnessed a rapid spread of Mobile and Wireless Information Technology (MWIT), which includes mobile devices such as mobile phones, PDA, smartphones, pocket computers, wireless networks and other technologies such as RFID (Radio Frequency Identification), as well as information systems accessed through these technologies (AGAR, 2004). Castells (2008) notes that, by 2007, mobile phone ownership or access has reached $50 \%$ of the entire world population. While estimates suggest that there will be at least 5.4 billion fixed and mobile phone subscriptions worldwide by 2010 , this does not mean that 5.4 billion people own a telephone (LING and DONNER, 2009). Conservative estimates assume a total of 3.4 billion mobile users. Due to the fast diffusion of mobile technology, Castells (2008) asserts that social research lags behind in trying to understand the new patterns of communication that emerge from the use of these technologies, as well as its impact and influence on many aspects of social life.

In current academic literature, there are several studies that focus on MWIT use and its impact on individual users or specific societies or groups (as those presented in KATZ, 2008), but there are still few studies that examine its effects on organizations. For Sorensen and others (2008), enterprise mobility -that is, the use of mobile devices for enterprise operations - creates new organizational forms to manage the way how people work collaboratively. Besides an increase in mobile technology applications, there are efforts to improve organizational efficiency and effectiveness. Although these issues are very important to organizational practice, its relevance is not reflected in the current literature on IS, which has dedicated relatively little attention to corporate mobility (SORENSEN and others, 2008).

This is due in part to the relegation of technology to the background in organizational sciences. It reflects the role played by IT in organizations in the 1980s. It was primarily used to automate existing operations and to increase communication speed (ZUBOFF, 1988, ZAMMUTO and others., 2007). However, organizational innovations using IT since the 1990s have shown new ways of organizing, which demands a careful analysis of the mutual shaping of IT and organizations.

We can also highlight the scarcity of academic studies showing criteria, typologies, frameworks or models to evaluate actual results of corporate investments in MWIT adoption. This is particularly true in regard to services, which tend to adopt these technologies in a higher proportion (MATHIASSEN and SORENSEN, 2008). If we consider a more precise focus on the service sector, there is an array of possibilities for mobile applications in public and governmental services, which can involve a wide geographical area and a potentially significant number of users. Therefore, it is relevant to generate references that can help to evaluate MWIT adoption results in this context.

The evaluation of IT adoption results is important to provide feedback to managers, increase organizational learning and diagnose gaps and opportunities for future improvements. However, this is not an easy task, since the evaluation of IT adoption results has different levels of analysis (macro, sector, firm, applications or stakeholders) as well as different consequences such as economic, organizational, social, managerial etc. (SMITHSON and HIRSCHHEIM, 1998).

This paper presents data from a research project that aims to assess results of MWIT adoption for service provision by public organizations. The research is based on a case study about the use of MWIT by IBGE (The Brazilian Institute of Geography and Statistics). IBGE is a Brazilian federal institution under the Ministry of Planning which is the main statistical information provider in the Country, attending several segments of the civil society and governmental spheres (IBGE, 2008).

In 2007, IBGE innovated by replacing paper questionnaires with electronic questionnaires accessed by census workers in field work via PDAs, in a complex census operation. This census operation involved three different surveys: (1) the National Register of Addresses for Statistical Purposes (known as the CNEFE survey); (2) population count in cities up to 170,000 inhabitants; and (3) Agricultural Census. This case of MWIT application received national and international attention, since IBGE deployed 82,000 mobile devices in this operation, which took place in a country of continental size with many different local realities. Therefore, it represents a unique situation that is worth documenting and evaluating in order to inform other cases of MWIT applications in public services, particularly in similar local realities, such as in South America.

This article is structured as follows: Section 2 presents the theoretical base of the research. Section 3 explains its methodology and analyses the data gathered in the case study. Section 4 presents a summary of results, a discussion and some final comments.

\section{THEORETICAL BACKGROUND}

MWIT afford resources for organizational processes such as provision of mobile communication, location-based 
services, support for mobile workers and emergency services in health care and military and public security, among others (ZHANG and YUAN, 2002).

Geser (2004) indicates that MWIT such as cell phones increases the ability of organizations to manage geographically distant units, and also to interact with customers in a context of mobility. Organizational structures can become more flexible, since it is possible to make rapid changes in the face of emerging conditions.

Welin-Berger (2004) points out internal and external gains with MWIT application in organizational processes. Internally, there are efficiency gains, such as receiving requests made remotely; reduction of back-office tasks (as generation of visit reports, which can be done during fieldwork); direct access to information about inventory and delivery time by fieldworkers, and also direct access to product information, manuals, technical documentation etc. from anywhere. From an external perspective (that is, customers), there are gains such as easy access to product order information (sent via mobile devices) and services offered through a mobile channel, as well as context-aware information. All these possibilities can generate organizational quantitative gains such as cost reduction in administrative tasks and logistics, efficiency gains in fieldwork and increased revenue (such as via mobile sales). They can also generate benefits such as better planning and location of mobile workforce, error reduction and better inventory control, as well as faster and more accurate information and communication (WELIN-BERGER, 2004).
Scornavacca and Barnes (2008) claim that mobile technologies allow business transformation (automation, information sharing etc.), efficiency (productivity gains and cost reduction), effectiveness, and particularly: flexibility, ubiquity ("do anything, anytime, anywhere" with MWICT support), connectivity, interactivity and locationawareness for organizations.

However, typologies, models or frameworks for assessing MWIT adoption results in organizations are still scarce. Scheepers and Mckay (2004) present one of the few studies that classified results of MWIT adoption according to three types of benefits:

- Type 1 -related to people's motivation and satisfaction with technology adoption, combined with better data quality and data exchange;

- Type 2 - related to efficiency and productivity gains; and

- Type 3 - effectiveness gains in a company, involving customer satisfaction and retention, and increases in revenue.

This typology follows the same rationale of some generic models for assessing IT adoption results, such as those proposed by DeLone and McLean (1992), Mirani and Lederer (1998), Mahmood and Soon (1991) and Smithson and Hirschheim (1998). These models are widely referenced and replicated in IS literature and can also be taken into account to evaluate results obtained with MWIT use - see a summary of the main variables considered by these models in Exhibit 1 .

Exhibit 1 - Variables for assessing IT adoption results in organizations

\begin{tabular}{|l|l|l|}
\hline \multicolumn{1}{|c|}{ VARIABLE } & \multicolumn{1}{c}{ CONCEPT } \\
\hline Information Quality & Ease of access to information, information quality and information relevance \\
\hline System Quality & Flexibility, ease of use and system sophistication \\
\hline Use & Frequency of access and number of reports provided \\
\hline User satisfaction & Satisfaction with a specific system \\
\hline Individual impact & Productivity, individual efficacy, decision-making and awareness toward the business \\
\hline Organizational impact & Costs reduction, staff reduction, increase in revenues, improvements in organizational results \\
\hline Competitive advantage & IT provides competitive advantage to a company \\
\hline Suppliers & IT improves management of suppliers \\
\hline Market & IT helps to identify market trends and forecasts, increase sales and anticipate customer needs \\
\hline Inter-organizational effectiveness & IT helps to improve organizational communication and coordination \\
\hline
\end{tabular}

Source: Gable, Sedera and Chan (2003); DeLone McLean (1992); Mirani and Lederer (1998); Mahmood and Soon (1991); Smithson and Hirschheim (1998). 
These models consider features of private sector organizations, that is, orientation towards profitability in a competitive market. Some variables, such as flexibility gains, better decisions, improvements in communication, coordination of activities, cost reduction or increase in staff productivity can also contribute to evaluate IT adoption results in the public sector.

Authors such as Heeks (2002) and Peters, Janssen and Engers (2004) emphasize that governments are seeking new ways to increase their efficiency and effectiveness, reduce administrative costs and respond quickly to social needs, as well as to comply with new laws.

However, evaluating IT investments in the public sector demand the consideration of public organizations' idiosyncrasies. Private organizations are usually willing to invest in IT in order to gain competitive advantages, and obtain economic and financial benefits. In public organizations, there are political objectives and system development frequently aim at meeting the needs of the different stakeholders involved (CRESSWELL and others, 2006).

Avgerou and others (2005) highlight that ICT (Information and Communication Technology) is a powerful tool to promote a culture of trust and participa- tion among different sectors of society and to strengthen "social contracts" that are essential for an equitable and sustainable development. Beyond improving efficiency and effectiveness, ICT use can influence issues such as agility and confidence in services provided by public organizations. Authors such as Avgerou and others (2005) and Smith, Martin and Noorman (2008) argue that corruption and bureaucracy reduction must be addressed by ICT use in government.

Irani and others (2005) show that IS result evaluations in the public area must go beyond traditional models, exploring issues such as: understanding mechanisms of decision making in IT investments within the organization; understanding the concept of "value" and its multidimensional aspects; assessing the nature (that is, intangible, tangible, financial and non-financial) of IS/ICT use benefits. This type of evaluation has to consider the complexity of evaluating an incremental system development, technology integration and updates.

The framework proposed by Irani and others (2005) contributes to IS adoption evaluation in governmental institutions (Figure 1).

Our research considers this framework (Figure 1) to

Figure 1 - A framework for public sector ICT/IS evaluation

\section{Culture \& Structure}

Constraints

- Available resources

- Departmental structure attitudes

Attitude

- To technology and IS

- IS/IT literacy

- Perceived costs

- To risk

- To corporate planning

- To collaboration
IS Evaluation

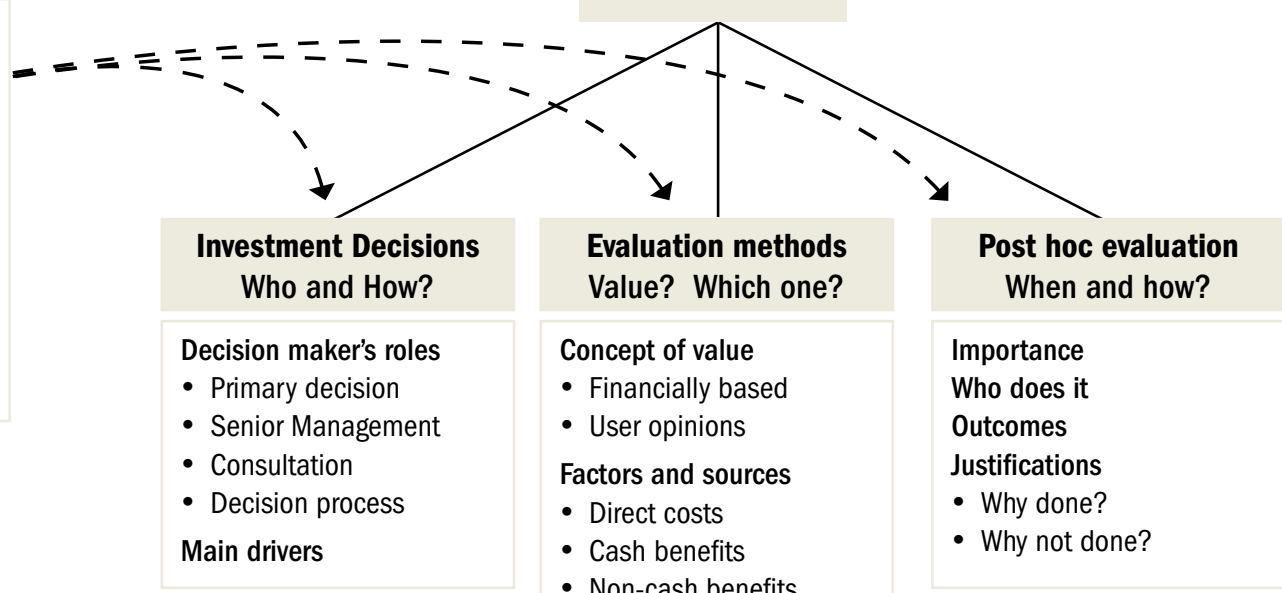

- Non-cash benefits

- Indirect costs

- Dis-benefits

- Risks

Choice of methods

- Methods used

- Methods not used

- Criteria 
evaluate MWIT adoption in the IBGE case. This framework was considered because it highlights the main elements and players involved in the ICT/IS adoption processes by a governmental organization, starting with the investment decision-making process, which should consider issues such as costs, benefits and risks. Moreover, it involves understanding who decides and how. We must also consider that the public sector context involves governmental investment policies and the government model that was adopted at the time of evaluation.

Another important element in this framework for ICT/ IS evaluation is the concept of value and the choice of an evaluation method. The concept of value for the public sector is unclear (BANNISTER, 2001; IRANI and others, 2005). Productivity measurement in service delivery is complex, particularly in public services, because they involve political and administrative issues as well as voters or constituents (BANNISTER, 2001).

It is important to note that in this framework (Figure 1 ), culture and organizational structures are regarded as players that influence all the other elements. Irani and others (2005, p. 67) emphasize that "the pervasive influence of organizational culture and structure means they should be seen as a major driver in all decision-making processes."

Finally, this framework indicates that there should be an assessment of the technology's post-implementation phase, which should evaluate its relevance and the results achieved, what should be (but is not) done, who fails to do it, why it is not done and what are the lessons learned throughout the implementation process.

However, the post-implementation phase analysis is not emphasized in this framework, because it focuses mainly on understanding "HOW" the whole process of adoption unfolds, with a systemic and political view of it - such as by considering who is involved, why decisions are made in certain ways etc. The framework does not provide a typology, a taxonomy or specific categories to evaluate "WHAT" are the final results of the post-implementation phase.

Therefore, the assessment of ICT/IS adoption results (at the post-implementation phase) was complemented by the reference of Danziger and Andersen (2002). These authors have proposed, after an extensive literature review, a taxonomy for evaluation of IT impact on public organizations. This taxonomy involves four areas, namely capabilities, interactions, orientations and value distribution, and their sub dimensions, as detailed in Exhibit 2.

According to Danziger and Andersen (2002), the IT impact on capabilities can be evaluated by examining whether IT had some effect on the way the public unit deals with its environment. The impact on capabilities is also related to changes in the quality of information

Exhibit 2 - Specific categories of IT impacts in public organizations

\begin{tabular}{|c|c|c|}
\hline DOMAINS & \multicolumn{2}{|c|}{ SPECIFIC CATEGORIES } \\
\hline I - Capabilities & $\begin{array}{l}\text { Information Quality } \\
\text { Data access } \\
\text { Data quality } \\
\text { Efficiency } \\
\text { Productivity gains } \\
\text { Staff reduction - substitution }\end{array}$ & $\begin{array}{l}\text { Improved (managerial) control } \\
\text { Time-saving measures } \\
\text { Effectiveness } \\
\text { Improved decision-making processes } \\
\text { Improved products and services } \\
\text { Improved planning }\end{array}$ \\
\hline II - Interactions & $\begin{array}{l}\text { Improved coordination-cooperation } \\
\text { Citizen-public sector interaction } \\
\text { Private-public sector interaction }\end{array}$ & $\begin{array}{l}\text { Citizen-citizen interaction } \\
\text { Organizational control and power }\end{array}$ \\
\hline III - Orientations & \multicolumn{2}{|l|}{$\begin{array}{l}\text { Improved decision-making } \\
\text { Emphasis on quantitative criteria (for decision-making) } \\
\text { Better structuring of problems } \\
\text { Increased discretion of decision makers }\end{array}$} \\
\hline IV - Value distribution & $\begin{array}{l}\text { Protection / improvement of the private sphere } \\
\text { Job satisfaction and enrichment } \\
\text { Job enlargement }\end{array}$ & $\begin{array}{l}\text { Protection of legal rights } \\
\text { Improved standard of health, safety and } \\
\text { well-being }\end{array}$ \\
\hline
\end{tabular}

Source: Danziger and Andersen (2002). 
available to political players and also to changes in organizational efficiency and effectiveness. The impact on interactions assesses how IT affects patterns of control and power, communication, coordination and cooperation among players performing a function in the public sector. In the domain of directions, IT can also be evaluated by considering its impact in political units' cognitive, affective, and evaluative considerations. In the value distribution domain, Danziger and Andersen (2002) indicate the assessment of values associated with improvements for citizens, as well as changes for public organizations' staff .

Thus, our study adopts the Irani and others (2005) framework and the Danziger and Andersen (2002) taxonomy complementarily, in order to cover all the process of ICT/IS adoption in the studied case, and also to clearly identify the main results achieved by one organization.

\section{THE CASE STUDY}

In this section we present the research methodology, followed by the case analysis.

\section{Methods}

The work adopts a qualitative research approach. We adopted a single case study as a research strategy. According to Yin (2001), this strategy is adequate when a case is rare or represents an extreme situation. The IBGE case can be classified as rare due to the massive and intensive use of MWIT by a public organization, supporting a mobile work performed throughout the territory of a country (which displays different physical, economical and cultural features).

According to the research goals, we collected data via semi-structured interviews and documentation analysis, focused on the project and the actual use of MWIT in the 2007 Census by IBGE.

Both the Irani and others (2005) framework (Figure 1) and the Danziger and Andersen (2002) taxonomy (Exhibit 2) were considered to gather the data, since they formed the main theoretical basis of the case study protocol.

A total of 21 individuals were interviewed at different relevant locations. At the IBGE headquarters in Rio de Janeiro, 11 people were interviewed (the IT Director, tree IT managers, tree IT technicians and four research technicians). At the state unit in Rio de Janeiro, two people were interviewed (the IT supervisor and the research coordinator). In other state unit in Rio Grande do Sul (a state in the South Region of Brazil), five people were interviewed (the IT supervisor, two research supervisors and two fieldworkers). At the state unit of Pernambuco (a state in the Northeast Region of Brazil), other tree people were interviewed (the state unit director, a research technician and the IT supervisor). The other source of raw data was a set of internal documents provided by the interviewees. Those were basically reports and presentations concerning the MWIT adoption project and its evaluation. The data gathering happened from February 2008 to March 2009.

The qualitative data analysis followed the steps indicated by Miles and Huberman (1994), including data gathering, data reduction, data display and conclusions drawing. We used content analysis procedures with the help of NVivo®. Furthermore, data from the interviews were triangulated with the documents collected and with observations carried out during the data collection process (that is, the mobile device adopted and the electronic questionnaires were observed). The data were categorized and organized around themes connected and ordered to follow an integrated scheme. These themes were linked to the main theoretical references adopted (Irani and others (2005) framework (Figure 1) and Danziger and Andersen (2002) taxonomy (Exhibit 2)). The categorizations were done after carefully reading and rereading the interviews (which were transcribed and entered into NVivo®).

\section{The IBGE Case}

IBGE (The Brazilian Institute of Geography and Statistics) is a public organization established in 1936. It has historically adopted innovative ITs to support its work. The first computer in Brazil was installed inside IBGE. Every time IBGE has engaged on a national, local, or special census, an update to its IT facilities has been made. The 2000 Population Census, for example, adopted high-speed scanners for reading the questionnaires. This technology was based on optical recognition of data and barcodes, recognizing both printed and handwritten characters, although at that time all the data gathering was paper-based.

The Population Census is a survey operation that is scheduled to occur once in approximately every 10 years. Other censuses such as the Agricultural Census and the Population Count, are scheduled to occur once in every 5 years. These are among the major surveys conducted by IBGE, in addition to a wide set of surveys on demographics, employment, economy, geography, prices, national accounts etc. (IBGE, 2009).

A census operation is a challenging task in a country the size of Brazil. In 2007 the IBGE Census held an integrated census operation, which included three different surveys. The first survey was the National Register of Addresses for Statistical Purposes (known as the CNEFE survey). 
This survey was first introduced in the 2007 Census. It aimed at updating the addresses of residential and nonresidential units in Brazil, including those in rural areas. In rural areas, IBGE captured geographical coordinates of health, religious and educational institutions, as well as households (IBGE, 2008). The second survey was the Agricultural Census. The third survey was a Population Count (IBGE, 2008). Due to budget restrictions, this count was restricted to municipalities with populations up to 170,000 inhabitants, where the population range impacts on the values provided by the Municipalities Participation Fund (known as FPM), managed by the Brazilian federal government (IBGE, 2008). A set of 21 cities with population above 170,000 was also included, thus corresponding to $97 \%$ of Brazilian municipalities (IBGE, 2008).

To perform this integrated census operation, IBGE involved approximately 90,000 people who worked in the process of data gathering, supervision, support and administration. In this 2007 Census, IBGE introduced the use of a PDA and electronic questionnaires for data gathering, thus abolishing the traditional use of paperbased questionnaires.

\section{Reasons to adopt MWIT}

The idea of using MWIT in survey processes at IBGE was originally considered in the 2000 Census. At that time, some PDAs were used to support fieldwork supervision . Initially conceived in the IBGE Department of Informatics, the goal was to bring IT to the process of field data gathering. This was a way to reduce the effort of data input occurring inside the IBGE back-office, as occurred in previous paper-based census. The delay in data input and tabulation, which was handwritten data, often containing errors, motivated a search for a technological solution that could optimize this process and eliminate rework and checks. The budget provided by the federal government for the 2007 Census also influenced the MWIT adoption. The Population Count was planned for 2005, five years after the last Population Census. However, the budget was severely reduced and only allocated by the government in early 2006. Therefore, IBGE had an unexpectedly short 12-month deadline to perform the whole census operation. They expected that MWIT use could allow for faster data gathering, since they could be sent to IBGE right after their field gathering. They also expected that resources could be saved, with fewer back-office staff working on data entry and checking within IBGE. The internal staff structure of IBGE has been reduced over time. The average age of its employees is high, many employees retire and there are difficulties in budgeting salaries for new workers. With an optimized fieldwork (conducted by temporary workers), IBGE expected to reduce costs with its internal structure.

There were also political pressures faced by IBGE to update the Population Count numbers, because it directly influences the funds transferred from the Brazilian federal government to municipalities. Some of these municipalities were filing suits against IBGE, demanding updated information. Therefore, MWIT use was considered as a solution to accomplish this task with the available time and funding.

Thus, the decision-making process for MWIT adoption in data gathering was not a smooth process within IBGE. An organizational consensus was required in the decision-making process of technology adoption, since there were risks associated with such type of massive, innovative technology adoption in a short period of time. An internal IBGE board was formed to speed up and manage this process, which was drawn across the organization.

The process of selecting the most appropriate MWIT was complex. Several requirements had to be considered, including a choice for a suitable technological infrastructure that could be used in future censuses and surveys. It is important to know that there is a lack of mobile device, operational system and wireless networks protocol standardization. This lack of standardization is a challenge for any process of MWIT adoption. There are several proprietary solutions, including different types of hardware, such as PDAs, smartphones, PocketPCs, tablets and sophisticated mobile phones. There are also different types of operating systems running on mobile devices, depending on the hardware, and each type of device allows for different systems and functionalities.

The search for the most adequate technology solution involved the analysis of approximately 16 mobile devices. The IBGE technical requirements were clearly defined, including the operating system (the most popular in the market at that time, Windows Mobile 5.0), the GPS functionality, $64 \mathrm{MB}$ of RAM memory and $128 \mathrm{MB}$ of ROM memory, as well as a rubber case to protect the device, among other features.

The mobile device chosen through a public bidding was the P550B Mio PDA, supplied by a Chinese company (Mitac). This device had Windows Mobile ${ }^{\circledR} 5.0$ operating system, Display of 3.5" TFT with touchscreen/65k colors/QVGA-240×320 pixels, 2 GB of on-board memory and flash memory with 64MB SDRAM/ SD/MMC/SDIO slot, GPS 20-channel SiRFstarIII, connectivity using USB v1.1, Bluetooth V2.0, built-in WLAN 802.11b+g module, 
built-in microphone, speaker/headphone/2.5mm earphone jack, 1200mAh battery, rechargeable Li-ion (1900). Dimensions: 4.15 " x 2.4" x 0.6 " (126 x 73 x 17.6mm). Weight: $6 \mathrm{oz}(170 \mathrm{~g})$.

However, one key element was beyond the control of IBGE managers: telecommunications infrastructure. In Brazil, this infrastructure is provided mostly by private companies under the supervision of ANATEL (The Brazilian National Telecommunications Agency). Mobile telephony in Brazil is one out of the three most expensive in the world (BERNSTEIN RESEARCH, as cited by VALOR ONLINE, 2010). Therefore, the chosen mobile device does not have seamless mobile connectivity. The survey data transmission from the field to the IBGE headquarters in Rio depended primarily on land lines. During the census operation, the IBGE technical team discovered that these fixed lines were precarious for data transmission, especially from the remote countryside and from small cities in Brazil.

The first pilot test of the 2007 Census mobile solution was performed in June 2006. The actual census data gathering began on April 16, 2007 and was finished in mid-September 2007. Within the surveyed areas, 82,000 mobile devices were used to collect the data. All devices were equipped with GPS (Global Positioning System). All data gathered in the field were transmitted to a central computer in the IBGE headquarters in Rio de Janeiro, through 515 IBGE agencies, with 1,106 collection points equipped with a PC and an ADSL connection or via satellite and 4.458 collection points equipped with a Bluetooth modem and a land line distributed throughout the Country.

Beyond the PDAs use and the infrastructure to send data directly from the field, we need to understand the importance and the radical innovation process of replacing paper-based questionnaires by electronic ones. Electronic questionnaires allow for a set of operations that were innovative, among them:

- Automatic checkpoints in each section of the questionnaire - This feature aimed to avoid input errors and missing values during data gathering.

- Automatic skipping - depending on the answers, the question flow path may vary, and therefore some questions are automatically skipped until the relevant one is reached, thus reducing time and errors during data gathering.

- Automatic sums when required (like the total number of cows in a farm).

- Data replication of a questionnaire applied to many people inside a household - Some data may be the same for people living inside a household. The possibility of replicating these data significantly reduces the data gathering time .

- Each electronic questionnaire has access to a built-in contextual help and a data dictionary to support fieldworkers.

- Specific warning alerts to census workers, informing them about the census processes.

- The GPS allowed for geo-referencing the surveyed sites.

\section{Training and adaptation to the new technology}

Similarly to the process of selection and implementation of the new technology, the process of training and adaptation to the MWIT had a short time allocated to its implementation, due to deadline pressures on the 2007 Census. Hence, this task was a challenge to IBGE.

The staff training used two complementary methods: distance learning (e-learning) and face-to-face classes. First, all the participants had a five-day training (selfinstruction) via e-learning, prior to the face-to-face training, which lasted eleven days on average. This face-to-face training was conducted in a "cascade system," with a small number of experts training other technicians, who in turn trained fieldworkers.

A crucial decision in the 2007 Census was the total exclusion of paper-based questionnaire use. This decision aimed at reducing costs of printing, distribution, collection and storage of paper questionnaires, which occupied a large area and demanded a very complex logistical operation. This decision caused some resistance from the permanent IBGE staff, people who were used to work with paper and had, therefore, a standard to compare to the new technology features. Common issues raised by permanent staff members included the difficulty in seeing the questionnaires on the PDA small screen, its short battery life and the delay in moving from one section to another inside the electronic questionnaire. According to interviewees, the MWIT adoption represented a "paradigm shift" and a personal hurdle for the permanent staff, which they had to overcome at great effort.

However, there was a different kind of behaviour when temporary workers worked with the same tools. These workers were mostly young people who easily adapted themselves to the new technology and offered no resistance to it. They even provided help to the permanent staff. Although this was a radical innovation process in IBGE, the MWIT adoption was performed in a short period of time (less than one year). Therefore, the technical and procedural adjustments in the mobile solution were incremental. The tests performed during implementation were 
not sufficient to cover all the possibilities and variables. This was in part due to the infrastructural diversity in a country like Brazil. For example, in many areas within the Country, especially those with difficult physical accessibility, it was very hard, if not impossible, in some specific places, to send the data via a land line. Any land line instability could damage the data, which required new sending. Another issue was the lack of technical support that is, people, logistics) to cover all the data gathering and transmission zones. The census operation capillarity is very high; therefore it was very difficult to quickly solve all the technical problems.

IBGE also had difficulties to precisely estimate the internal infrastructure required for data receiving at its headquarters. Due to the difficulties for sending the data from the field, there was often a data sending overload (like during working hours). IBGE had to maintain a complex internal infrastructure of network and servers to protect the data, which caused a certain delay in data receiving during peak hours.

Besides these technical shortcomings, IBGE was running three different types of survey in a single census operation (the CNEFE survey, the Agricultural Census and the Population Count) for the first time. Therefore, IBGE's internal organizational integration was also a challenge, since there was not a complete body of knowledge of all the consequences and challenges of the innovation process within the organization.

The IBGE case shows all the complexity of MWIT adoption in a public organization, highlighting several issues that must be taken into account to evaluate the adoption results, which is the central issue of the next section.

\section{Evaluation of the results of MWIT adoption}

As described in the previous section, the steps involved in a census are complex and include elements such as: people, equipment, telecommunications, infrastructure and logistics. Considering all these elements, IBGE applied the MWIT expecting to reduce the costs and time spent in the census operation.

With the use of a paper-based questionnaire, the data gathering time (during the interview with the citizen) was much longer, around $40 \%$ longer according to internal documents of IBGE. The optical reading step for data entry was eliminated. The reduction of time could also be extended to fieldwork supervision, since supervisors had access to a mobile IS that uses GPS-based data, allowing them to quickly oversee all the surveyed areas and the work performed by fieldworkers with precision. All these time savings along the process resulted in faster data pro- cessing and the census results being made available earlier to decision-makers (that is, the government and society).

Reducing the time of data gathering and data checking also enabled cost reductions with fieldworkers (who can apply more questionnaires in less time) and back-office staff, since it is no longer necessary to have a team to enter and check the data in the back-office after its gathering.

Cost savings were also obtained with the reduction of paper use during the Census. During previous census, there was a whole range of activities such as printing and storing questionnaires and logistics - that is, the delivery and return of questionnaires to IBGE from all the Brazilian states. All these costs were reduced, despite the amount invested in MWIT. The investment in MWIT can be amortized, because the mobile device can be used in other IBGE surveys.

Information quality was also identified as a key outcome of the MWIT adoption, because the data passed through automatic checkpoints inside the electronic questionnaire. Handwritten data in the paper-based questionnaires used to demand a careful checking at the IBGE back-office, which has changed now since it is checked during fieldwork. Therefore, the information that reaches the IBGE central computer is more consistent and accurate, thus reducing the "clean-up" rework and complementing the data.

Besides the quality of data gathered via electronic questionnaires, the GPS-equipped PDA also allowed for georeferencing the surveyed units. There were also increases in the quality of information available for fieldwork supervision, which helped to improve management work, productivity supervision and also fraud prevention during data gathering. The IBGE managers received information from the field faster; therefore, it was possible to monitor, through indicators, all the operation progress (like. how many missing questionnaires remained in a given area, how many of them were incomplete, the average number of questionnaires completed per day per census worker etc.).

Another result refers to the upgrade of the IBGE IT infrastructure. Not only the IT staff, but also all the MWIT users went through learning process in order to work with the MWIT.. This resulted in training of employees, who also had their work improved by accessing more sophisticated resources to perform it, including resources for checking the data gathered in the field. The interviewees pointed out that the MWIT adoption brought the opportunity to update and to train them in the use of a new technology and tools (electronic questionnaires, GPS etc.). The technology use went to the fieldwork and became 
part of the data gathering activity, which represented a significant change.

The contact with MWIT was an indirect gain for the census workers involved. The people recruited to collect the data usually belong to the local communities surveyed. In this sense, these census workers had a unique opportunity to use the PDA and all the technology involved in the process (electronic questionnaire, GPS etc.). This experience can be useful for them in future jobs in the market, since there are several types of mobile professionals that use similar devices to perform their work, such as salespersons, field technicians, consultants etc.

Finally, there was a strategic gain of agility and organizational effectiveness with the use of MWIT, allowing for delivering survey results faster. Therefore, several stakeholders benefit from the use of MWIT. The government obtains the information faster, which is necessary for making decisions related to public investment and social policies that directly affect citizens. Similarly, cost reduction in the census operation also consists in a benefit for the government and society (which funds the service through taxes).

In the next section we present a summary, a discussion and some final comments on this article.

\section{DISCUSSION AND FINAL REMARKS}

The IBGE case reveals a set of elements to be considered in the process of MWIT adoption for service provision by public organizations. The framework proposed by Irani and others (2005) helped to analyse these elements through the analysis of the processes of technology selection, implementation and diffusion in order to allow a proper evaluation of results. The adoption results in the IBGE case were also classified according to the other main theoretical reference considered in this research, namely Danzinger and Andersen's (2002) taxonomy - see Exhibit 3.

First, considering the MWIT adoption process, one can see that the selection of a new technology by a public organization is influenced by a set of complex elements, including cultural and structural organizational features, political pressures and the search for effectiveness. The permanent search for technological upgrades of the internal structure and technology in IBGE has influenced the choice for using MWIT, combined with budgetary restrictions and the search for efficiency. Irani and others (2005) highlight a key issue, which is the quality of the public services delivered. In this sense, the political pressures faced by IBGE influenced the MWIT used. The quest for speed in obtaining demographic data was very important considering the political context of this case.

The IBGE culture and structure also influenced the MWIT adoption process. It was a radical innovation process that was carried out by different areas and players within the organization. There were areas of resistance, but also massive collaboration in overcoming all the difficulties and unexpected events that unfold during technology use in the field.

The level of risk in the project was high in all senses: changing a strong culture (of paper-based work); training an "army" of almost 90,000 people in a short period of time; and supporting a new technology application in a wide geographical area.

One can realize that the complexity of spreading the IT into the field in a wide geographical area (which is common when we consider the delivery of public services) brings a set of challenges to be faced. Controlling and coordinating the entire operation with precision is an almost impossible mission. Both massive collaboration (that is, employees, organization, infrastructure) and virtual collaboration (via technology, local supervision, data transmission and receiving etc.) are very important components in the success of this endeavour (ZAMMUTO and others, 2007).

Complementarily, regarding the final results of adoption, one can also analyse the data with the support of Andersen and Danziger's (2002) taxonomy already presented in Exhibit 2. In Exhibit 3, we classify the research results according to this taxonomy. One can notice that the main results of MWIT adoption in the IBGE case are concentrated in the first domain (that is, capabilities), involving data and information quality and organizational efficiency and effectiveness improvements (including time savings and cost reductions). The use of MWIT also helped to deliver the information faster.

In the second domain (interactions), the MWIT use facilitated the interaction between the back-office and the front-office during the census operation, and also facilitated the interaction with citizens, by reducing the time spent to answer to a questionnaire, as an example.

In the third domain (orientations), the case shows that the MWIT helped to improve the IBGE manager's discretion and decision-making on fieldwork operations. It is important to highlight that this domain is not clearly explained by Danzinger and Andersen (2002). Their article does not provide a deeper discussion on how we can explore this domain in practice. It was difficult to gather data about it and consequently to further explore this domain in the discussion of research results. It can 
be pointed as a future research topic in order to improve their taxonomy.

In the fourth domain (value distribution), the adoption of MWIT has stimulated the qualification of the IBGE staff. There was also job enrichment, because census workers incorporated part of back-office tasks in their job, becoming responsible for taking care of data from the moment when they are gathered in the field. An interesting result in this domain is that the diffusion of MWIT among the 82,000 census workers can be seen as a case of digital inclusion, as already discussed.

Another important result is that, by providing more accurate field work supervision, the use of MWIT can help the public organization to prevent fraud and corruption during the census work. However, this aspect was not fully explored in the studied case. It is indicated as important issue for validation in future research.

An internal evaluation of the 2007 Census was performed by IBGE, and the results are now informing the 2010 Census, which have greater dimensions, with the use of approximately 250,000 mobile devices for field data gathering. IBGE also analysed other cases of ICT for data gathering with the support of CEPAL (The Economic Commission for the Latin America and the Caribbean). They analysed experiences in countries such as Colombia (a pioneer in the use of PDA for data gathering in census work in Latin America) Peru, Costa Rica and the US the analysis is described in Silva and Mansoldo (2007).

As a future research issue it will be interesting to deeply understand in which ways the lessons learned from the 2007 Census were absorbed in 2010. For instance, in 2010 the IBGE has implemented web questionnaires for the first time; they have also expanded the National Register of Addresses for Statistical Purposes with intensive use of GPS (IBGE, 2010).

Although the IBGE 2007 census provides an innovative case about the use of mobile technology by public organizations, no further analysis has been made on how the relationship between IT and organizations has changed the role of command and hierarchy in coordinating and controlling activities (ZAMMUTO and others, 2007). This is an important issue for future research.

We expect that by presenting a case of IT and organization in combination, as in the IBGE case, this article helps to clarify future research needs, and then, by showcasing its successes and shortcomings, we may contribute to further moves in the field.

The paper results are particularly useful for public organizations in similar local realities (like South America) that are applying or planning to use MWICT in public services, considering the needs of different stakeholders in wide geographical areas.

Exhibit 3 - Main results of MWIT adoption in the IBGE case

\begin{tabular}{|c|c|c|}
\hline DOMAINS & \multicolumn{2}{|c|}{ SPECIFIC CATEGORIES } \\
\hline I - Capabilities & $\begin{array}{l}\text { - Information Quality (information for census } \\
\text { - } \text { Dupervision and census results) } \\
\text { the field) } \\
\text { - Data quality (automatic check in data gathering) } \\
\text { - Efficiency (organizational agility) } \\
\text { - Productivity gains (in the census operation) } \\
\text { - Staff reduction (in back-office work) }\end{array}$ & $\begin{array}{l}\text { - Improved managerial control (of the census operation) } \\
\text { - Time-saving measures (time reduction in field work, in } \\
\text { back-office work, in service delivery) } \\
\text { - Effectiveness (cost reductions - staff costs, paper } \\
\text { costs, storage and logistics costs) } \\
\text { - Improved products and services (agility in delivering } \\
\text { public services) }\end{array}$ \\
\hline II - Interactions & \multicolumn{2}{|c|}{$\begin{array}{l}\text { - Improved coordination (of census work) } \\
\text { - Citizen-public sector interaction (time reduction in data gathering facilitates interaction with citizens) } \\
\text { - Organizational control and power (over the census work) }\end{array}$} \\
\hline III - Orientations & \multicolumn{2}{|c|}{ - Improved decision-making processes (on census management and to information clients - government, citizens etc.) } \\
\hline $\begin{array}{l}\text { IV - Value } \\
\text { distribution }\end{array}$ & \multicolumn{2}{|c|}{$\begin{array}{l}\text { - Job satisfaction and enrichment (Employees obtain knowledge and skills in the use of a new technology) } \\
\text { - Job enlargement (census workers absorbed part of back-office tasks) } \\
\text { - Dissemination of MWIT in the society (census workers) } \\
\text { - Better fieldwork supervision can improve fraud/corruption detection }\end{array}$} \\
\hline
\end{tabular}




\section{REFERENCES}

AGAR, J. Constant touch: a global history of the mobile phone. London: Icons, 2004

AVGEROU, C; CIBORRA, C; CORDELlA, A. and others. The role of information and communication technology in building trust in governance: toward effectiveness and results. Report - Inter-American Development Bank, 2005.

BANNISTER, F. Dismantling the silos: extracting new value from IT investments in public administration. Information Systems Journal, v. 11, n. 1, p. $65-84,2001$

CASTELLS, M. Afterword. In: KATZ, J. Handbook of mobile communication studies. Cambridge: MIT Press, 2008.

CRESSWELL, A. M; BURKE, G. B; PRADO, T. Advancing return on investment analysis for government IT: a public value framework. Research Paper, Center for Technology in Government. Available at: http://www.ctg. albany.edu/. Access on: 09.08.2008.

DANZIGER, J. N; ANDERSEN, K. V. The impacts of information technology on public administration: an analysis of empirical research form the "golden age" of transformation. International Journal of Public Administration, v. 24, n. 5, p. 591-627, 2002.

DELONE, W; McLEAN, E. Information systems success: the quest for the dependent variable. Information Systems Research, v. 3, n. 1, p. 60-95, 1992.

GABLE, G. G; SEDERA, D; CHAN, T. Enterprise systems success: a measurement model. In: 24TH INTERNATIONAL CONFERENCE ON INFORMATION SYSTEMS. Proceedings. Seattle, 2003.

GESER, H. Towards a sociological theory of the mobile phone. Available at: http://socio.ch/mobile/t_geserl.htm. Access on: 20.10.2004.

HEEKS, R. Reinventing government in the information age. London: Routledge, 2002.

IBGE. Censo 2007. Available at: http://censos2007.ibge.gov.br/. Access on: 04.03.2008.

IBGE. IBGE - A instituição - principais funções. Available at: http://www. ibge.gov.br/home/disseminacao/eventos/missao/instituicao.shtm. Access on: 24.04.2009.

IBGE. Censo 2010. Available at: http://www.censo2010.ibge.gov.br/ aperfeicoamento.php. Access on: 04.10.2010.

IRANI, Z; LOVE, P. E. D; ELLIMAN, T. and others. Evaluating e-government: learning from the experiences of two UK local authorities. Information Systems Journal, v. 15, n. 1, p. 61-82, 2005.

KATZ, J. Handbook of mobile communication studies. Cambridge: MIT Press, 2008.

LING, R; DONNER, J. Mobile communication. Cambridge: Polity Press, 2009.

MAHMOOD, M. A; SOON, S. K. A comprehensive model for measuring the potential impact of information technology on organizational strategic variables. Decision Sciences, v. 22, n. 4, p. 869-897, 1991.
MATHIASSEN, L; SØRENSEN, C. A theory of organizational information services. Journal of Information Technology, v. 23, n. 4, p. 313-329, 2008.

MILES, M. B; HUBERMAN, M. A. Qualitative data analysis: an expanded sourcebook. Thousand Oaks, CA: Sage, 1994.

MIRANI, R; LEDERER, A. L. An instrument for assessing the organizational benefits of IS projects. Decision Sciences, v. 29, n. 4, p. 803-838, 1998.

PETERS, R. M; JANSSEN, M; ENGERS, T. M. Van. Measuring e-Government impact: existing practices and shortcomings. In: 6TH INTERNATIONAL CONFERENCE ON ELETRONIC COMMERCE. Proceedings, 2004

SCHEEPERS, H; McKAY, J. An empirical assessment of the business value derived from implementing mobile technology: a case study of two organizations. In: 12TH EUROPEAN CONFERENCE ON INFORMATION SYSTEMS. Proceedings, 2004.

SCORNAVACCA, E; BARNES, S. The strategic value of enterprise mobility: case study insights. Information, Knowledge, Systems Management, v. 7, n. $1-2$, p. $227-241,2008$

SILVA; C. S. da; MANSOLDO, H. F. Study of the use of ICT for data collection. Internal Document of IBGE, 2007

SMITH, M. L; NOORMAN, M. E; MARTIN, A. K. Accountabilities, automations, dysfunctions, and values: ICTs in the public sector. London School of Economics and Political Science. Working Paper Series 169, 2008

SMITHSON, S; HIRSCHHEIM, R. Analysing information systems evaluation: another look at an old problem. European Journal of Information Systems, v. 7, n. 3, p. 158-174, 1998.

SØRENSEN, C; AL-TAITOON, A; KIETZMANN, J; and others. Exploring enterprise mobility: lessons from the field. Information Knowledge Systems Management, v. 7, n. 1-2, p. 243-271, 2008

VALOR Online. Tarifas de celular no Brasil estão entre as mais caras do mundo. Available at: http://www.valoronline.com.br/?impresso/ tecnologia_E_telecomunicacoes. Access on: 01.09.2010.

WELIN-BERGER, M. W. M-Commerce. In: KORNAK, A; TEUTLOFF, J; WELIN-BERGER, M. Enterprise guide to gaining business value from mobile technologies. Hoboken: Wiley, 2004

YIN, R. K. Estudo de caso: planejamento e métodos. Porto Alegre, Bookman, 2001

ZAMMUTO, R. F; GRIFFITH, T. L; and others. Information technology and the changing fabric of organizations. Organization Science, v. 18, n 5 , p. $749-762,2007$

ZHANG, J; YUAN, Y. M-commerce versus Internet-based E-commerce: the key differences. In: 8TH AMERICAS CONFERENCE ON INFORMATION SYSTEMS. Proceedings, 2002.

ZUBOFF, S. In the age of the smart machine: the future of work and power USA: Basic Books, 1988. 